\title{
'STEM education and innovation are essential for national success' A profile of Australia's Chief Scientist, Ian Chubb
}

\author{
Beverley Head
}

\begin{abstract}
Beverley Head interviews Australia's Chief Scientist, Professor Ian Chubb AC. This article plots his scientific and academic journey, and reveals his concerns regarding the need to boost Australia's performance in science, technology, engineering and mathematics (STEM) in order to transform the national economy.
\end{abstract}

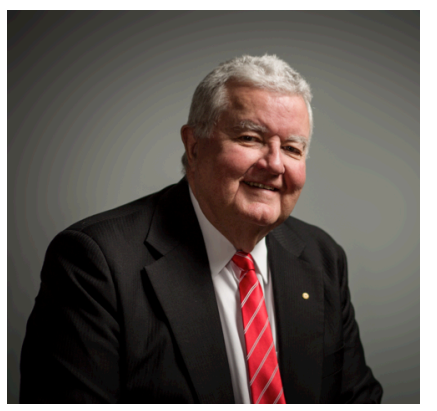

In the late 1940s a grey-suited teacher called Mr Honey sent a small boy outside, into the schoolyard, sparking a lifelong passion for science and learning.

The Menzies Creek Primary School had one room and one teacher for its 20 children; Mr Honey needed to concentrate on the older students so would buy himself some time by sending the younger children outside to study the natural world.

Concentrating on the movement of a worm, the appearance of a butterfly, or the emergence of a cicada, the young Ian Chubb started to develop a fierce curiosity about the natural world. Mr Honey, who Professor Chubb still characterises as the most influential teacher he ever met, sparked an interest in, and passion for, science that would sustain Chubb to the very top of his profession.

Professor Ian Chubb AC is now Australia's Chief Scientist. His role is to provide high-level independent advice to the prime minister and other government ministers on science, technology and innovation. He is also the nation's prime advocate for Australian science internationally.

"The real issue is that we have some very good research in Australia," he says. But he tempers that, noting; "The average research is not spectacularly good but it's OK. We could do better and be more strategic about it."

He offers the metaphor of science policy being akin to a gardener who wants to grow flowers of a specific colour. "We tend to throw the seeds up and hope we get the right colour," where 
he says in other countries, particularly the US, UK, Sweden, Germany and many countries in Europe, gardening policy would have already ensured that the right mix of seeds was present to get the desired flower colour.

Part of the problem he believes is a lack of interaction between business and education. Only 4 per cent of businesses in Australia collaborate with universities he says, compared to 50 per cent in the UK. "That is simply not good enough, and it's particularly important in Australia because our researchers tend to be found in higher education institutions.

"The British have taken a very strategic approach to build bridges. We've talked about it for 20 years, it's about time we did it.”

Chubb also believes that there is a need to foster closer links with international research efforts noting that although about 3 per cent of the world's research outcomes emerge from Australia - that still means that 97 per cent are found overseas. "How do we link our research to that?"

In terms of the "flower colours" Australia needs, Chubb says; "The reality for us is that there are things that are particularly important to Australia. We need to understand the environment better: water, our aquifers, how we can be a food bowl for anywhere when the weather patterns have changed so much.

"I believe we can't innovate something if we don't know about it - so we need to be linking to other countries and other organisations," and analysing global information sources in order to better prepare Australian industry for the challenges ahead.

It's for that reason that he believes digital platforms and high speed communications networks are essential underpinnings for effective e-collaboration adding; "That's why Australia can seriously lament the fact that the number of ICT graduates has fallen from 4,600 a year to 2,500 and the number of female graduates in ICT has dropped from 1,500 a year to 500."

In early 2014 Chubb wrote an article published in the Australian Financial Review which lamented the 36 per cent decline in students starting an IT degree since 2001, and the even starker 41 per cent decline in students graduating with IT degrees in the same timeframe.

Chubb, who boasts a storied biography, has an intimate understanding of science, tertiary education and the need to encourage graduates across the STEM (science, technology, engineering, maths) disciplines.

Studying chemistry and biochemistry as an undergraduate instilled an interest in the human brain, which he describes as "the ultimate puzzle - why it works and why it doesn't". 
After a couple of years at Belgium's University of Ghent he took up a research position at Oxford University for several years before returning to Australian in 1978 to the new school of medicine at Flinders University.

Asked to nominate his greatest achievement as a scientist Chubb modestly claims it came through "accumulating a good team of excellent people. When I came back to the new medical school in Adelaide the lab was a room with a sink and nothing else." After relocating the sink Chubb set about building a team of 15 people who together advanced neuroscience. Among his colleagues, both at Oxford and Adelaide, was Chubb's lifelong friend, Professor Peter Somogyi, today acknowledged as one of the world's greatest neuroscientists and now director of Oxford University's anatomical neuropharmacology unit.

One hot October night, swinging in a backyard hammock with a glass of wine to hand, Chubb's wife suggested that his life could perhaps be a bit harder. It led him to look for other opportunities and he accepted the role of deputy vice chancellor at Wollongong and honorary professor of biology.

Chubb's final science experiment was conducted in 1986, since when he has worked in senior roles in tertiary education (senior deputy vice chancellor of Monash University, vice chancellor of Flinders University and vice chancellor of the ANU along with a series of senior advisory roles in the sector) before taking on the role as Chief Scientist in 2011.

His tenure officially ends in May next year. Chubb, now 70, quips that "this is no country for old men" although he does not rule out a further term noting the appointment of Chief Scientist is a question for the government of the day.

Age does not seem to have wearied him; Chubb remains passionate about the need for effective science policy and most particularly the supporting education infrastructure needed to develop the nation's skills base.

Throughout his tenure Chubb has stressed the need for a more strategic approach to STEM education from primary level up. In an address to the $17^{\text {th }}$ National Engineering Heritage Conference in November last year Chubb noted that Australia spends less than 3 per cent of primary teaching time on science and 18 per cent on some form of mathematics. This by 2011 had translated to just 9.6 per cent of students studying advanced maths compared to 14.1 per cent 16 years earlier.

As Chubb noted, more attention must be paid to the time spent teaching science to primary students, societal attitudes to science as a career, and the pre-requisite subjects for university admission. 
During that November address he stated: "We should commit to developing a long term and cohesive national strategy for STEM in Australia." Asked whose responsibility this should be, Chubb says: "This isn't for government, universities or business to fix on its own. We are all inside the tent to work out the solution. “

Without access to skills, Chubb worries that national innovation will stagnate.

"Four per cent of Australian companies have taken new products and services to the international market, 4 per cent to the domestic market - given there is some crossover that means that some number equal or less than 8 per cent of innovation is for the market. I would think that is a fairly small level of innovation.

"Some keep innovation inside the company - but when that is over 60 per cent, compared to 8 per cent focused on new products, the proportions seem odd." Chubb questions whether innovation's contribution to competitive advantage is properly understood by industry and whether incentives to support innovation are properly aligned.

In August 2013 in a joint article with the CEO of the Business Council of Australia, Jennifer Westacott, Chubb discussed the need for "a 50-year agenda founded on Australia's capacity to innovate, adapt and value add in traditional sectors".

Again he expounded the need for collaborative platforms, noting that "It will be collaboration that allows us to create the systems and the environment that foster and drive innovation...innovation can only flourish when people and organisations have the requisite skills and abilities and when they operate in an environment that provides them with the scope and incentive to collaborate and innovate".

In terms of the industrial sectors which hold most promise for Australia's long term prosperity, Chubb notes: "We have grown medical devices and biotechnology from a really small businesses ten years ago to a fairly substantial base.

"In quantitative terms you get greater innovation out of your smaller businesses - although that is a little unfair to larger companies which do innovate.

"We need to encourage people employing often 10-100 people and that's where the university links should come in - where they can learn that some people might be using a different alloy or a different IT system. The university researchers can walk along the path with them.

"We have got to think of what sort of economy we want in 10, 15, 20 years because it all starts with education. We are in a global market and it is no use thinking that we can attract people here because Australia is a nice place to live. 
"We need enough computer science people and big data skills so that we can be looking at sharing data and conducting e-research."

In terms of the technological underpinnings to support national and international eresearch and collaboration Chubb notes that "It seems fairly simple that the better we can communicate at high speed and on a big scale the better it will be".

Slow Internet speeds would inevitably prove a hindrance. "Communications at speed and with volume and dependability - the benefit to us all would be huge."

While Chubb has been a vocal and publicly active Chief Scientist, he needs also to ensure his messages resonate at the highest level of Government, and he has recommended that Australia borrow a leaf from the US and establish a body equivalent to the US Presidential Council of Advisors of Science.

"From what I have seen of the US system it works well. They have strategic research priorities that we have never had - and out of that one result was the programme to create technology teachers for schools."

He acknowledges the US funding model differs from that in Australia, but he does not view the funding regime as an insurmountable barrier.

Precisely how Australia lifts its game in science and technology is still unclear. That it must is unquestionable.

"When I sit down and think of the challenges facing us as a people and the whole planet...science will be there at the core.

"We have got to understand how to work with the community and expectations. It's really important we understand the natural world, the constructed world, how biology works and there is a lot of physics and maths in the smartphone we carry in our pocket."

Asked about the legacy he hopes to leave as Chief Scientist, Chubb says that he hopes to drive an embedded and strategic approach to science and innovation; an acceptance of science as a core issue rather than an optional extra; and an increase in the number of science students who are "fascinated by the intrinsic awesomeness of science".

Whether they go on to become scientists after graduating is less important. "They can go and work in a bank and be awesome there - but they will be infiltrating all segments of the economy," says Chubb.

A solid STEM foundation and industry-research collaboration will be essential if Australia and Australian industry is to become seriously, strategically and internationally engaged he argues. 
It's a long way from Menzies Creek and Mr Honey. "As you grow up some interests increase more than others. I was interested in how biology worked and when I think back on it, which I haven't before this moment, it was when the teacher sent us out to look at butterflies, worms and cicadas.

"The teacher had to teach six classes in one room. While he was teaching other grades he would set us a task. If you did it well you were given a pencil. If you did it really well there was a pencil with an eraser. People like me wanted the one with the eraser."

Talking to Professor Chubb today it's clear that he wants the pencil with the eraser not just for himself - but for the nation.

Cite this article as: Head, Beverley. 2014. "STEM education and innovation are essential for national success': A profile of Australia's Chief Scientist, Ian Chubb'. Australian Journal of Telecommunications and the Digital Economy 2 (1): 30.1-30.6. DOI: http://doi.org/10.7790/ajtde.v2n1.30. Available from: http://telsoc.org/journal 